\title{
Daylight and Energy Consumption Assessment of a School Building Through Multi-Objective Optimization and Clustering Technique
}

\author{
Mario Alves da Silva, Rafael de Paula Garcia, Joyce Correna Carlo \\ Federal University of Viçosa, Brazil \\ mario.a.silva@ufv.com \\ rafael.pgarcia@ufv.com \\ joycecarlo@ufv.com
}

\begin{abstract}
Multi-objective problems usually employ conflicting objective functions, making the Simulation-Based Optimization process return a set of solutions. This study applies a clustering technique to analyze and characterize the solutions obtained in a school building optimization problem, maximizing daylight while minimizing energy consumption. We modeled the geometry using the Rhino + Grasshopper platform, following an existing building's characteristics. The parameters were the building's dimensions, openings' height, solar devices' and light shelves' reflectance, solar devices' distance from the facade, rotation angle, and depth of light shelves. We applied a clustering technique to group solutions according to their parametric similarities at the end of the optimization process. This approach made it possible to establish guidelines to support the designer's choice of the combination of parameters that best fits his purposes.
\end{abstract}

Keywords: Simulation-based optimization, Genetic algorithm, Daylight modeling, Clustering, Machine Learning

\section{Introduction}

Over the past decades, it is possible to see the growing usage of tools that allow a more complex building performance assessment (Nguyen et al., 2014). Among them is Grasshopper, a visual programming platform associated with the Rhinoceros modeling software and enables modeling at different levels, from initial design to building performance evaluation (Shi et al., 2016). Grasshopper allows parametric modeling, simulation, and optimization in the same platform, from more simple methods to complex modeling and performance evaluation processes. 

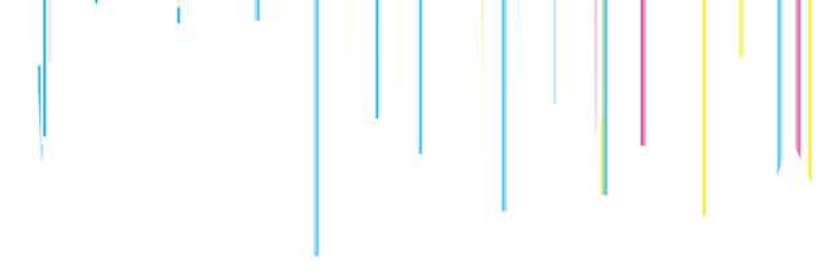

Parametric modeling associated with performance-based design allows assessing different building designs and their respective performance (Farouk et al., 2019; Oxman, 2017; Turrin et al., 2011). Through Simulation-Based Optimization (SBO), the design process consists of several design tools and strategies such as parameterization, simulation, and optimization. These processes aim to find optimal solutions that satisfy pre-established performance conditions by the simulator, and this type of approach is growing in architecture (Fonseca et al., 2017; González \& Fiorito, 2015; Granadeiro et al., 2013; Lucarelli et al., 2019; Shi et al., 2016). In this way, combining different approaches can lead to buildings with high performance on various aspects, such as comfort, energy consumption, and lighting.

Despite the growing evolution of computational power, Simulation-Based Optimization processes (SBO) have been applied to complex problems, searching for promising solutions and avoiding simulating all the combinations of parameters. Multi-objective problems usually employ conflicting objective functions, making the SBO process return a set of optimal solutions. Choosing one of them is not always an easy task. Therefore, this study aims to apply a clustering technique to analyze and characterize the solutions obtained in a school building optimization problem, maximizing the Useful Daylight Illuminance (UDI) while minimizing the energy consumption with HVAC and artificial lighting systems.

\section{Methods}

\subsection{Problem formulation, simulation, and optimization}

This study uses a school building of the Federal University of Viçosa's Architecture and Urban Planning department. The building comprises classrooms and labs. The actual building is surrounded by vegetation and other buildings from the same department, although this study considers the geometry isolated without any surrounding shade. Da Silva et al. (2018) present a more detailed characterization of the building, such as zoning, openings detailing, and other aspects. Figure 1 shows the main façade of the building used for this study. 


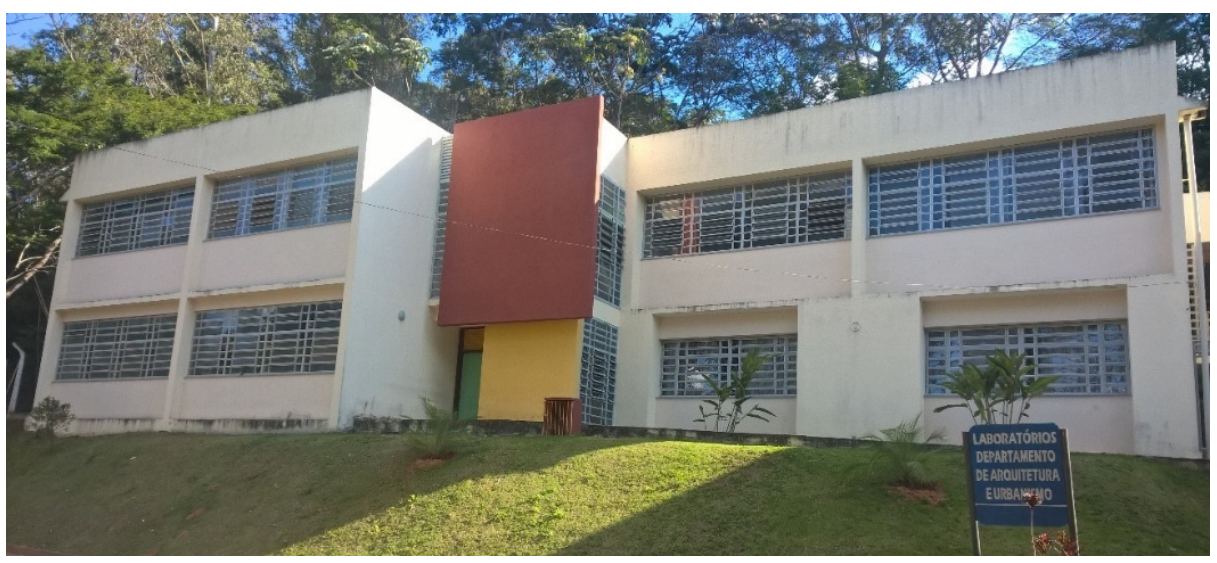

Figure 1. Building's main façade. Source: Da Silva et al. (2018)

For the parametrization, we divided the building into two main sectors divided by the region with the red plane, consisting of a circulation area. The first sector consists of the portion on the left side of the red wall, and the second section, located on the right side of the circulation zone. This division allowed modification on the floor plan of both sectors in an independent way, so both sectors can separately have improvements on width and depth. Table 1 shows the parameters defined to assess daylight potential and energy consumption.

Table 1. Building parameters

\begin{tabular}{|c|c|c|c|}
\hline Parameter & Description & Bounds & Type \\
\hline$x 1$ & sector 1 width & {$[10,14]$} & continuous \\
\hline $\mathrm{x} 2$ & sector 1 depth & {$[10,14]$} & continuous \\
\hline$x 3$ & sector 2 width & {$[10,14]$} & continuous \\
\hline$x 4$ & sector 2 depth & {$[14,17.05]$} & continuous \\
\hline$x 5$ & opening's height & {$[1.65,1.95]$} & continuous \\
\hline x6 & $\begin{array}{l}\text { distance between the shading } \\
\text { devices and the openings }\end{array}$ & {$[0.25,1]$} & continuous \\
\hline$x 7$ & shading devices opening angle & {$[0,90]$} & continuous \\
\hline$x 8$ & light shelves depth & {$[0.4,0.8]$} & continuous \\
\hline x9 & $\begin{array}{l}\text { shading devices solar } \\
\text { reflectance }\end{array}$ & {$[1,78]$} & discrete \\
\hline $\mathrm{x} 10$ & light shelves solar reflectance & {$[1,78]$} & discrete \\
\hline
\end{tabular}

Source: Adapted from Da Silva et al. (2018)

In the optimization problem, the main façade has shading devices in all eight windows and also light shelves in the corresponding zones (Fig. 1). Parameters $x 5$ to $x 10$ regulate the geometric and luminous aspects of both shading devices and light shelves. Figure 2 shows the relation between the parameters presented in Table 1 and the actual building geometry. Figure 2 also shows the shading devices' integration into the building model. 


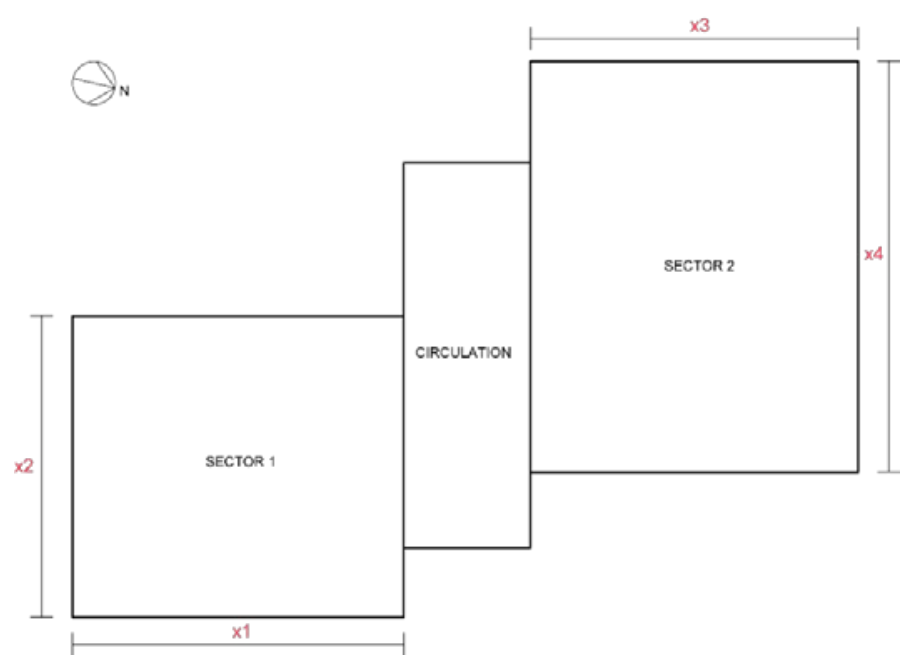

(a)

(b)

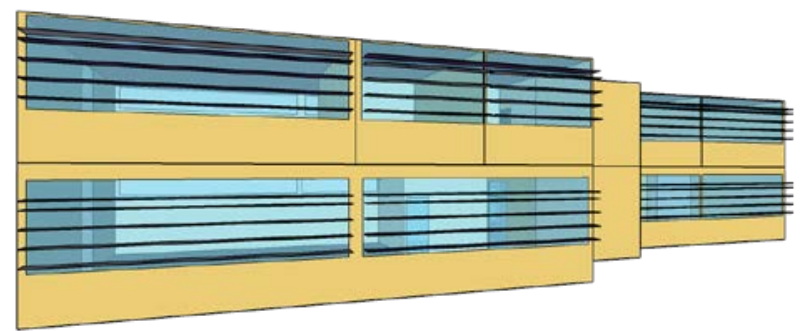

(c)

Figure 2. Schematic floor plan with the building's geometric parameters (a), a schematic section with shading devices and light shelves' parameters (b), and integration of shading devices in the main façade. Source: Adapted from Da Silva et al. (2018) 
The optimization problem maximized daylight through Useful Daylight Illuminance (UDI) and minimized energy consumption (EUI) with HVAC systems and lighting. UDI is a metric that measures the availability of daylight in a specific range through an entire year. For this study, we used the range of 300 - 3000lx (Mardaljevic et al., 2012). The EUI index measures the consumption in kilowatt-hour divided by the consuming area.

We use Grasshopper for Rhino to model the building and perform the simulations and the optimization process. We use Archsim and DIVA to link daylight availability to the thermal model's schedules and intensity of electrical lighting.

For the optimization process, we used a population genetic algorithm for multi-objective optimization known as HypE (Bader \& Zitzler, 2011) which is available in the Octopus plugin. HypE is an algorithm that uses the Pareto dominance strategy to evolve a population of solutions. Thus, the algorithm's objective is to find a curve, called the optimal Pareto curve, where all solutions are non-dominated. Therefore, at the end of the optimization process, it is considered that all solutions in this curve are equally optimal. In practical problems, the optimizer must choose one of these solutions to implement. This post-optimization step requires expertise that is not always a simple task.

We define population size as 70 , and we did not determine a maximum number of generations. We also set elitism as 0.5 , mutation probability as 0.1 , mutation rate as 0.5 , and crossover rate as 0.8 . This way, we observed the process until it reached a converge condition.

\subsection{Clustering technique and solutions characterization}

To analyze the solutions obtained by the optimization process, we applied an unsupervised clustering technique extensively used in the literature known as K-Means (Likas et al., 2003). This technique partitions all the solutions into $\mathrm{k}$ groups based on mutual parameters and fitness functions. K-means starts by choosing $\mathrm{k}$ solutions as centers for $\mathrm{k}$ clusters. The other solutions are then associated with each center according to their proximity (usually, the Euclidean distance is the metric used to measure similarity). After that, the centers are repositioned according to the average of the solutions in each cluster. The other solutions are again associated with the new centers. This process repeats until the centers remain static or until reaching the maximum number of iterations. An essential and challenging task of K-means is defining the value of $\mathrm{k}$. In this work, we used a voting criterion based on 26 different methodologies. This tool is available for free on RStudio, through the NbClust package (Charrad et al., 2014).

We assessed fitness functions and parameters values based on each cluster to observe the main groups' characteristics. This way, it is possible to associate parameter configurations with particular performance aspects, leading to recommendations to enhance performance. 
Figure 3 shows the method applied in this study as a schematic process, pointing out essential elements and steps.

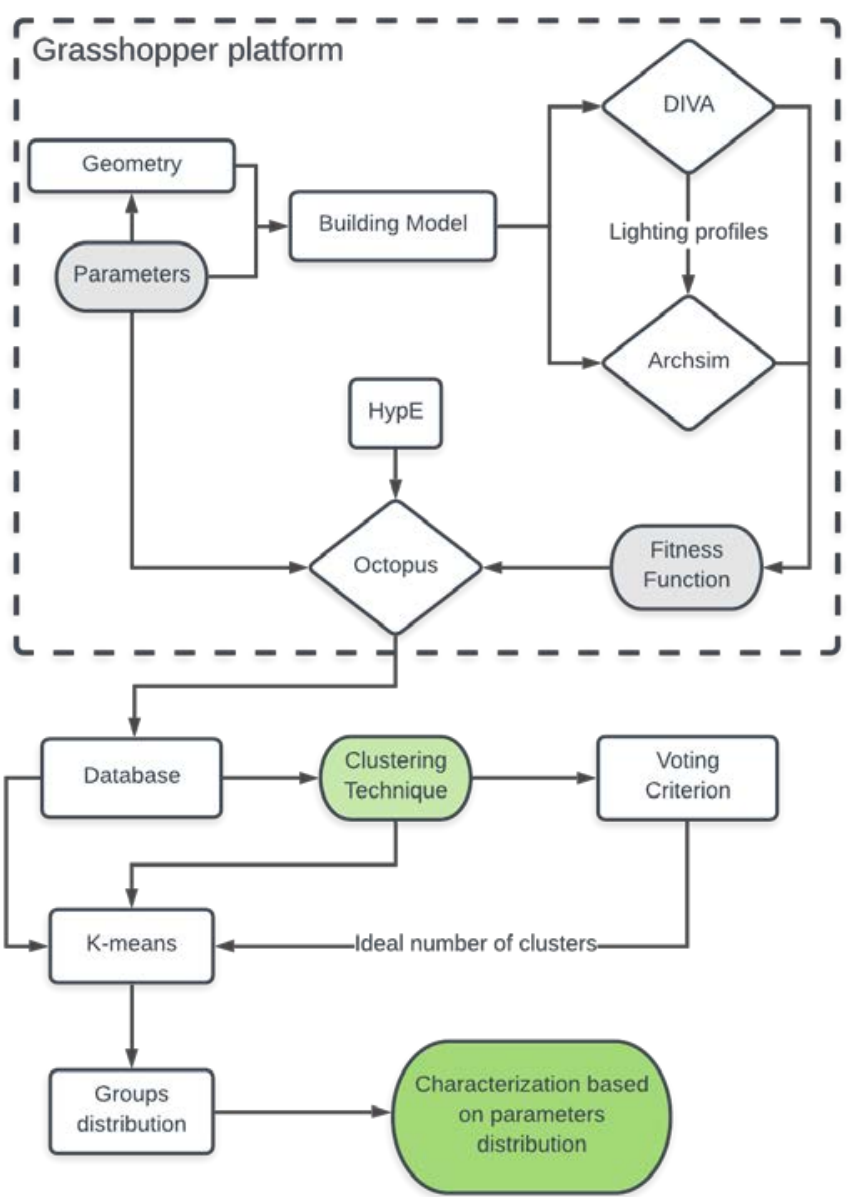

Figure 3. Schematic process of the method adopted in this study.

\section{Results and discussion}

After 54 generations, we stopped the optimization process based on Octopus' visual convergence indicators. To apply the clustering technique, we use the 3448 unique solutions obtained in the 54 generations. We chose to use all unique solutions because the Pareto Front only returned 12 solutions (Fig. 4). Thus, applying a clustering technique would demand a computational 


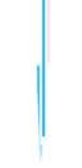

processing method with high cost when analyzing solution by solution would be a feasible task.

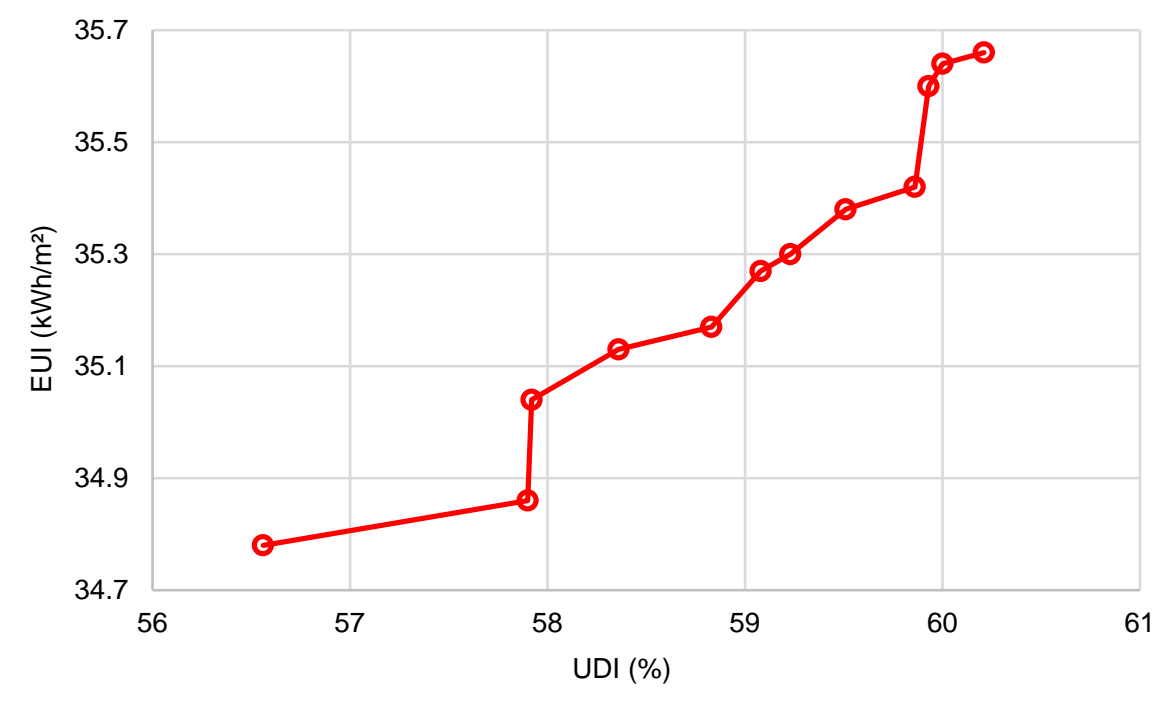

Figure 4. Distribution of the best solutions on the Pareto curve.

Based on the voting criterion, the ideal number of clusters is 3 . Figure 5 shows the distribution of the unique solutions and similarities between groups. Group 1 has EUI values in a range similar to Groups 2 and 3 but lower UDI values. Since the objective of this problem is to minimize the EUI while maximizing the UDI, the Pareto curve should form in the lower right portion of the graph. Group 1 has $22 \%$ of all solutions, Group 2 has $45 \%$, and Group 3 has $33 \%$. This proportion also allows observing convergence since the optimization process directs the search around the best solutions. These results show that the optimization focused a significant part of the budget on improving both fitness functions simultaneously.

Groups 2 and 3 have a similar UDI range, but Group 2 has the best solutions for UDI and EUI. So, in a general way, an initial analysis of the clusters' distribution indicates that Groups 1 and 3 have solutions that prioritize one and just one of the fitness functions, and Group 2 satisfies both. Therefore, whenever possible, group 2 should have priority when choosing a solution for implementation. For projects with flexibility in the incidence of daylight but still with reduced energy consumption values, solutions belonging to the boundary between groups 1 and 2 can provide good results.

Figure 5 also shows solution overlaps. That is, different configurations lead to the same value for UDI and EUI. Group 3 shows a few solutions with UDI between $26 \%$ and $38 \%$. Groups 2 and 3 also overlap a few solutions, around 38 and $40 \mathrm{kWh} / \mathrm{m}^{2}$. 


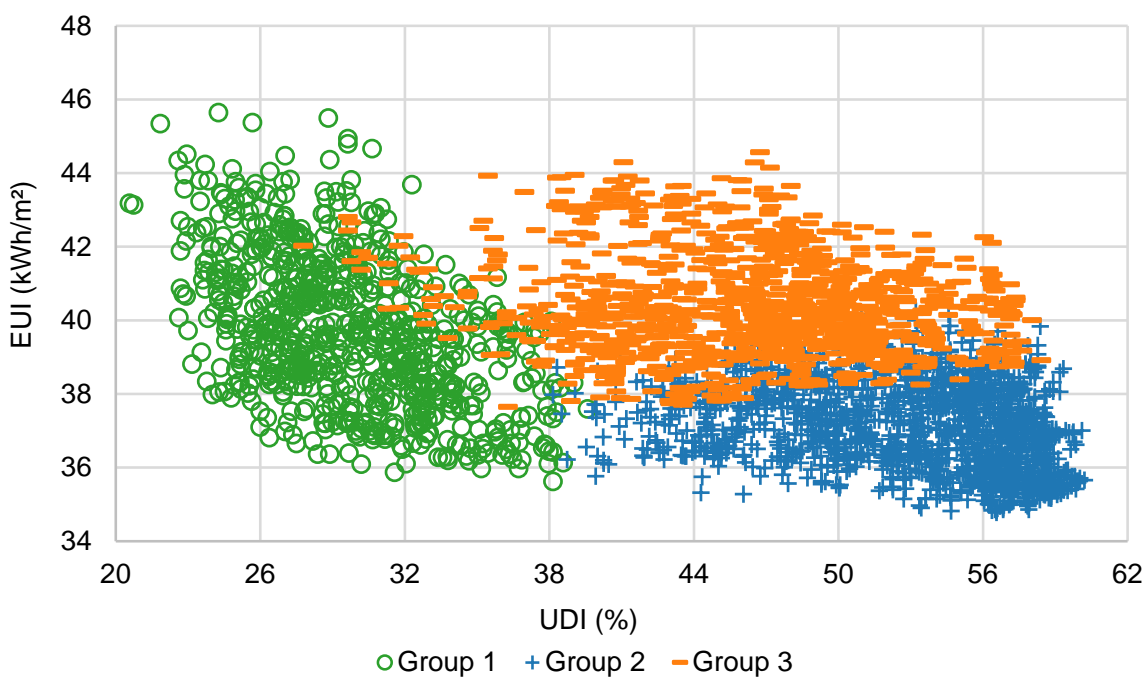

Figure 5. Solutions distribution and grouping according to the K-Means technique.

Figure 6 shows parameters' distribution based on the cluster groups. Building width ( $x 1$ and $x 3$ ), shading devices distance from opening ( $x 6$ ), light shelves depth ( $x 8$ ), and both reflectance parameters ( $x 9$ and $x 10)$ had a similar impact on the clusters since the range of values assumed by these parameters only have a small variability between groups. So, they have a minor effect on both UDI and EUI, leading to good and worse fitness function values.

Building depth ( $x 2$ and $x 4$ ) and openings' height ( $x 5$ ) have the most significant impact on solutions grouping, especially in determining the range of values that lead to the best solutions, that is, solutions that satisfy both daylight distribution and energy consumption. Lower values lead to better results for building depth since daylight presents a better distribution in shallow rooms, and a small floor area reduces energy consumption. Opening height works reversely, so higher values lead to higher openings that allow more daylight in the room. However, bigger windows in the main façade impact less on energy consumption since shading devices block significant portions of the solar radiation from reaching indoor spaces. 


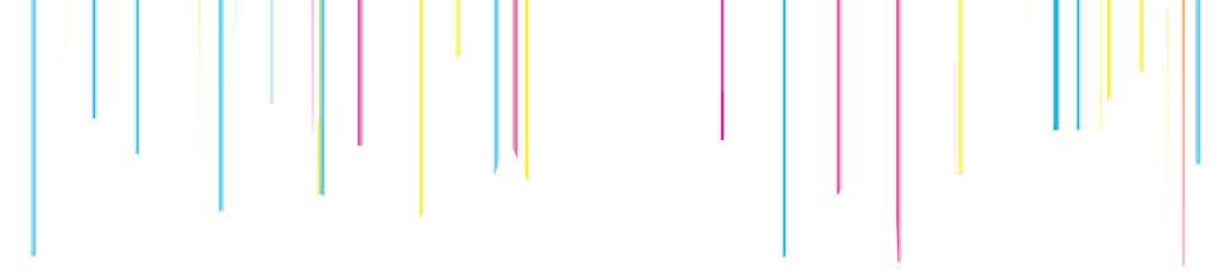

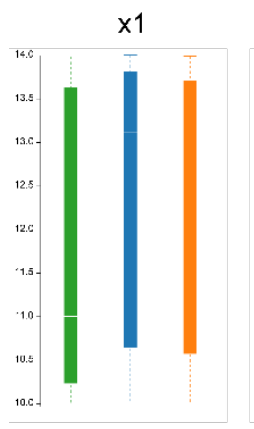

$\times 6$ $\mathrm{x} 2$

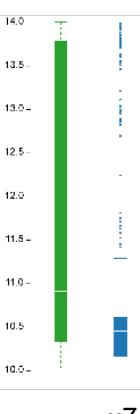

$\times 3$

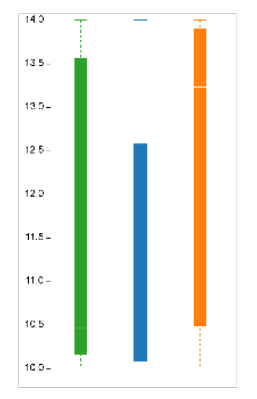

$\times 8$ $x 4$

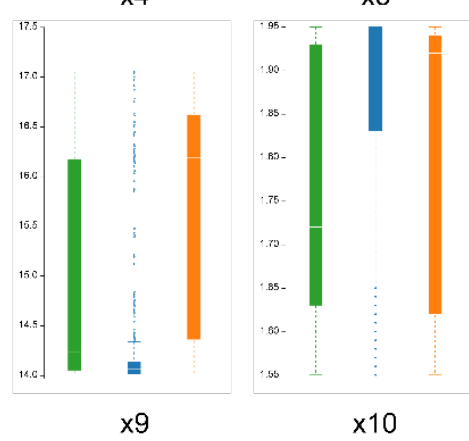

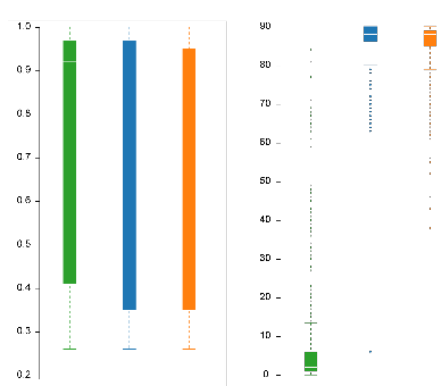
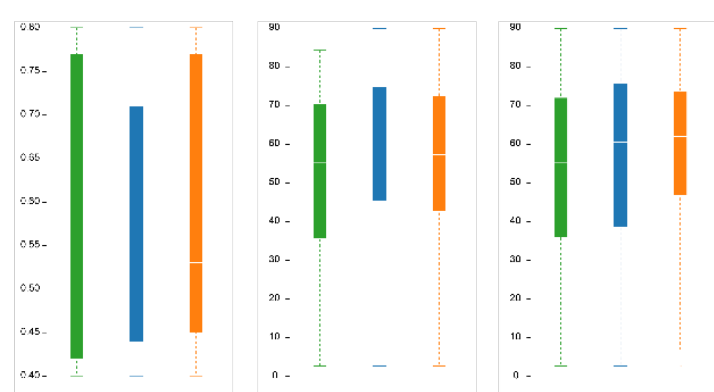

Figure 6. Parameters distribution based on cluster groups from Figure 4 (green for Group 1, blue for Group 2, and orange for Group 3).

Shading devices' opening angle (x7) also shows a significant impact. This parameter has a similar range for Group 1 and Group 2, previously described as groups with the best UDI values, highly related to the daylight fitness function. So, the high values representing less daylight blocking through openings lead to better indoor daylight levels. Though, this configuration can achieve solutions with low and high consumption levels. These results conclude that shading devices opening angle depends on the other three significant parameters to provide the best solutions.

The results allow concluding that building depth, openings height, and shading devices opening angle are the parameters that most impact daylight distribution and energy consumption. So, this work's results can lead to investigations on these specific parameters in future research and design solutions that provide the best and worst performance. The clustering method adopted can also be reproduced in other works, allowing grouping and characterization based on fitness functions and parameters.

The clustering methodology for the characterization of solutions from a multi-objective optimization process proposed in this work must ideally be applied only to solutions contained in the optimal Pareto curve when it presents many solutions. Still, considering that the SBO process is computationally expensive and that, therefore, the solutions simulated are valuable, classifying 
all of them into well-characterized groups can provide technical insights into the use of one solution over another.

\section{Conclusion}

Multi-objective Simulation-Based Optimization (SBO) processes allow obtaining solutions that satisfy more than one objective. This study focused on the post-processing phase of an SBO process by applying a clustering technique to characterize the solutions obtained and answer which design parameters have the most significant impact on the proposed problem.

The clustering technique based on a voting criterion determined that solutions should be in three different groups. The grouping resulted in one group with the best results for EUI, one with the best results for UDI, and the third with solutions that presented the best values for both fitness functions. The characterization based on each group formation allowed us to conclude that buildings depth, openings height, and shading devices' opening angle are the parameters that most impact building performance.

This study provides a new approach to group and characterizes optimization solutions, and the method is replicable to other databases, including problems with a significant number of Pareto solutions.

Acknowledgements. This study was financed in part by the Coordenação de Aperfeiçoamento de Pessoal de Nível Superior - Brasil (CAPES) - Finance Code 001.

\section{References}

Bader, J., \& Zitzler, E. (2011). HypE : An algorithm for fast optimization. Evolutionary Computation, 19(1), 45-76. https://doi.org/10.1162/EVCO_a_00009

Charrad, M., Ghazzali, N., Boiteau, V., \& Niknafs, A. (2014). NbClust: An R Package for Determining the Relevant Number of Clusters in a Data Set. Journal of Statistical Software, Articles, 61(6), 1-36. https://doi.org/10.18637/jss.v061.i06

Da Silva, M. A., Carlo, J. C., \& Silva, L. B. (2018). Parametric modeling and building performance: lighting and energy simulation based optimization through genetic algorithms. Cadernos PROARQ (UFRJ), 30, 150-176.

Farouk, A., Eldaly, H., \& Dewidar, K. (2019). Parametric Design As a Tool for Performative Architecture. Journal of Al-Azhar University Engineering Sector, 14(50), 148-157. https://doi.org/10.21608/auej.2019.28490

Fonseca, L. P. G., Nunes, V. D. L., Santana, L. O., Carlo, J. C., \& César Júnior, K. M. L. (2017). Otimização multiobjetivo das dimensões dos ambientes de uma residência unifamiliar baseada em simulação energética e estrutural. Ambiente Construído, 17(1), 267-288. https://doi.org/10.1590/s1678-86212017000100135 
González, J., \& Fiorito, F. (2015). Daylight design of office buildings: Optimisation of external solar shadings by using combined simulation methods. Buildings, 5(2), 560-580. https://doi.org/10.3390/buildings5020560

Granadeiro, V., Pina, L., Duarte, J. P., Correia, J. R., \& Leal, V. M. S. (2013). A general indirect representation for optimization of generative design systems by genetic algorithms: Application to a shape grammar-based design system. Automation in Construction, 35, 374-382. https://doi.org/10.1016/j.autcon.2013.05.012

Likas, A., Vlassis, N., \& J. Verbeek, J. (2003). The global k-means clustering algorithm. Pattern Recognition, 36(2), 451-461. https://doi.org/https://doi.org/10.1016/S00313203(02)00060-2

Lucarelli, C. de C., Carlo, J. C., \& Martínez, A. C. P. (2019). Parameterization and solar radiation simulation for optimization of a modular canopy. PARC Pesquisa Em Arquitetura e Construção, $\quad 10, \quad$ e019017. https://doi.org/10.20396/parc.v10i0.8653371

Mardaljevic, J., Andersen, M., Roy, N., \& Christoffersen, J. (2012). Daylighting Metrics: Is there a relation between Useful Daylight Illuminance and Daylight Glare Probabilty? Proceedings of the Building Simulation and Optimization Conference BSO12. http://infoscience.epfl.ch/record/179939

Nguyen, A. T., Reiter, S., \& Rigo, P. (2014). A review on simulation-based optimization methods applied to building performance analysis. Applied Energy, 113, 10431058. https://doi.org/10.1016/j.apenergy.2013.08.061

Oxman, R. (2017). Thinking difference: Theories and models of parametric design thinking. Design Studies, 52, 4-39. https://doi.org/10.1016/j.destud.2017.06.001

Shi, X., Tian, Z., Chen, W., Si, B., \& Jin, X. (2016). A review on building energy efficient design optimization rom the perspective of architects. Renewable and Sustainable Energy Reviews, 65(November), 872-884. https://doi.org/10.1016/j.rser.2016.07.050

Turrin, M., Von Buelow, P., \& Stouffs, R. (2011). Design explorations of performance driven geometry in architectural design using parametric modeling and genetic algorithms. Advanced Engineering Informatics, 25(4), 656-675. https://doi.org/10.1016/j.aei.2011.07.009 